\title{
The need for measurable standards in mental health interpreting: a neglected area
}

\author{
Jan Cambridge, ${ }^{1}$ Swaran P. Singh, ${ }^{2}$ Mark Johnson ${ }^{3}$
}

The Psychiatrist (2012), 36, 121-124, doi: 10.1192/pb.bp.110.031211

${ }^{1}$ Professional interpreter in the public services; ${ }^{2}$ University of Warwick, Coventry; ${ }^{3}$ De Montfort University, Leicester

Correspondence to Jan Cambridge (jancambridge@uwclub.net)

First received 19 May 2010,

final revision 2 Sep 2011, accepted

4 Nov 2011
Summary This editorial offers an overview of mental health service provision across different languages and cultures in the UK. It is increasingly recognised that mental health service users with limited English proficiency are rendered doubly vulnerable by the combination of their illness and their language difficulties. Only recently has the importance of safe, coherent, nationally available interpreting, translation and language support (ITALS) been recognised by healthcare providers. We review the challenges within the interpreted interaction, some reasons for the scarcity of qualified and accredited ITALS suppliers, and some solutions to the ITALS problem.

Declaration of interest J.C.'s current PhD study concerns interpreting in mental health services. S.P.S. and M.J. are her supervisors.
Interpreting is more than a matter of dual literacy. In a medical specialty such as psychiatry, language is the principal diagnostic and therapeutic tool. Many aspects of interpreting in such settings present challenges. These include: structural differences between language types; problems of speech and thought disorder in psychiatry, and disordered, mumbled or very rapid speech; varietal differences between languages (e.g. American and British English, varieties of Arabic); idiolect; and cursing. Practical needs include having a line of sight on speakers' faces, ${ }^{1,2}$ and having a clear mutual understanding between the clinician and the linguist of role boundaries, procedures and constraints. Interpreting, translation and language support (ITALS) must be delivered to a highly trained professional standard, and yet ITALS remains a neglected area of provision in British healthcare. The bulk of research has focused on adverse events attributed to inadequate interpreting, ${ }^{3-5}$ but very little research exists into the processes, outcomes and effectiveness of interpretation in mental health settings.

Over the past 30 years, linguists have put great effort into developing professional structures, qualifications and standards for interpretation in healthcare. Training and practice standards for professional interpreters are not statutory, however, and are widely ignored. There is no empirical evidence about how interpreting services and interpreter training should be delivered. National occupational standards for interpreters were first developed by the National Centre for Languages and reviewed in $2004 .^{6}$ These standards set the entry level for professional interpreters in the public services at National Qualifications Framework Level 6, equivalent to a first degree. Registration with the professional regulator, the National Register of

†See commentary, pp. 124-125, this issue.
Public Service Interpreters, founded in 1994, requires both professional education (e.g. Diploma in Public Service Interpreting) and proven practical skills - but registration is not statutory.

Trained interpreters are in very short supply, especially in languages not used frequently in the UK. A bilingual person is one whose command of two languages is at nearnative speaker level in both languages. The Institute of Linguists Educational Trust, a recognised awarding organisation, and the associated charity of the Chartered Institute of Linguists offer nationally accredited interpreting qualifications such as the Diploma in Public Service Interpreting and an additional mental health module. Local planning for recruiting and training interpreters is made problematic by the lack of data on language groups in the UK. No official sources of data exist on the languages used by service users with limited English proficiency or their level of English ability, which led to a call for a language competence question to be included in the 2011 census. Since no relevant language data are kept in hospitals, it is difficult to quantify or predict need. The National Health Service Resource Allocation Weighted Capitation Formula is based on language difficulty data that are 10-15 years out of date. ${ }^{7}$

Clinicians often take the informal or family interpreter on trust in the absence of a trained professional. The risk is that in such circumstances parts of a message may be left out or altered to protect the patient or a cultural value. For example, if in response to the question 'Have you taken any over-the-counter preparations to help you sleep?' the patient says 'I went to a Shaman [traditional healer] but the medicine he gave me no longer helps with my bad dreams', a family interpreter may see this as pejorative to their cultural group and interpret the answer as 'This is the first time I have seen a doctor'. 


\section{Challenges in interpreting}

The linguistic complexity and cognitive challenge of switching a message from one language to another involves a series of tasks in the space of a few seconds. The list includes listening for meaning, remembering, paraphrasing, reformulating, changing the syntax, and finding words in the other language.

Syntax (word order) change is especially taxing where the languages used are of different structural types. Subject-verb-object and subject-object-verb languages are built in opposing order. In a subject-verb-object language such as English, a sentence might run: 'Mary walked slowly to the bus stop because it was sunny and she was early.' If only a short chunk of this sentence is delivered, it is possible to discern a degree of meaning; the verb at the beginning gives key information about what Mary did and when. In a subject-object-verb language such as Arabic, Punjabi or German, Mary's journey would be described as 'Mary slowly because it was sunny and she was early to the bus stop walked.' Thus, the interpreter has to switch the word order completely when rendering the message into a differently structured language. If the speaker is breaking the sentence into chunks of a few words at a time, the interpreter will struggle to deliver much sense.

Even when both languages are of the same structural type, very formal language causes the verb problem. In one incident in an English magistrates' court, the prosecutor read out the charge: 'Juan Fulano it is alleged that, [pause] on the 14th of July last, [pause] in company with a person or persons unknown [pause] and with malice aforethought, contrary to the Public Order Act of 1986 you ...' At this, the prosecutor leaned over the interpreter, who was scribbling furiously, and asked: 'Are you going to speak?' 'Yes', the interpreter replied, 'Give me a verb and I'll start.' Up to that point there was nothing intelligible she could have said in Spanish. This is one of many such personal experiences of author J.C.

The impulse for most courteous people is to try to 'make sense' of what they hear. There is an ingrained urge in interpreters to 'tidy up'. Listeners will want to hear meaning and may challenge the interpreter's version if it unexpectedly fails to deliver any. Interpreters working in mental health must not tidy up and must be willing to relay what they may perceive as meaningless talk, which is remarkably difficult to do. Disjointed or incoherent speech is one of the rare public service situations in which an interpreter must relay word for word. Conversely, word-forword relay of coherent talk can produce nonsense even across two similarly constructed languages.

For example, the Spanish phrase 'no está en casa', translated word for word, means: 'Not he, she, it or you is temporarily in house'. In context, the phrase means 'He's not at home'. Interpreting for a patient with a formal thought disorder is therefore specifically challenging and problematic.

\section{Interpreting techniques}

Professional interpreters have various ways of interpreting, in terms of both performance models (Table 1) and interpreting techniques. The technique used in administrative interchanges using closed questions is

\begin{tabular}{|c|c|c|}
\hline Impartial model & Community model & Advocacy model \\
\hline The interpreter: & The interpreter: & The interpreter: \\
\hline $\begin{array}{l}\text { Does not give advice or their own opinion } \\
\text { except on language and cultural matters }\end{array}$ & Does give advice or their own opinion & Does give advice or their own opinion \\
\hline $\begin{array}{l}\text { Intervenes to ask for clarifications, } \\
\text { interpreting the intervention to the other } \\
\text { party }\end{array}$ & $\begin{array}{l}\text { May refer the patient to other agencies } \\
\text { or negotiate with or challenge the service } \\
\text { provider } \\
\text { Intervenes for clarification }\end{array}$ & $\begin{array}{l}\text { May refer the patient to other agencies } \\
\text { or negotiate with or challenge the service } \\
\text { provider }\end{array}$ \\
\hline $\begin{array}{l}\text { Does not explain complex terms or concepts } \\
\text { but asks the clinician to do so and relays the } \\
\text { explanation; the term is often left in English } \\
\text { after that to avoid multiple coinages by } \\
\text { multiple interpreters }\end{array}$ & $\begin{array}{l}\text { Explains complex terms or concepts, but may } \\
\text { ask for assistance from the clinician }\end{array}$ & $\begin{array}{l}\text { Explains complex terms or concepts, but } \\
\text { may ask for assistance from the clinician }\end{array}$ \\
\hline $\begin{array}{l}\text { Acts as the alter ego or other self of each } \\
\text { speaker, reflecting their speech style, level } \\
\text { of language and emotions as far as possible }\end{array}$ & $\begin{array}{l}\text { Reflects the register and speech style of } \\
\text { the patient }\end{array}$ & $\begin{array}{l}\text { Mediates between the patient and the } \\
\text { service provider, negotiates, and may see } \\
\text { themselves as a representative of their } \\
\text { community }\end{array}$ \\
\hline Attempts to relay all that is meant & $\begin{array}{l}\text { Is often viewed an as 'advocate' or 'cultural } \\
\text { broker' who goes 'beyond the traditional } \\
\text { neutral role of the interpreter' }\end{array}$ & \\
\hline $\begin{array}{l}\text { Remains impartial and displays empathy } \\
\text { while maintaining a professional distance } \\
\text { from both parties }\end{array}$ & $\begin{array}{l}\text { Remains impartial and displays empathy } \\
\text { while maintaining a professional distance } \\
\text { from both parties }\end{array}$ & $\begin{array}{l}\text { Guides the patient through the encounter, } \\
\text { giving information on rights and services }\end{array}$ \\
\hline $\begin{array}{l}\text { Clarifies linguistic and cultural issues as } \\
\text { relevant or requested }\end{array}$ & $\begin{array}{l}\text { Clarifies linguistic and cultural issues as } \\
\text { relevant or requested }\end{array}$ & $\begin{array}{l}\text { Clarifies linguistic and cultural issues as } \\
\text { relevant or requested }\end{array}$ \\
\hline
\end{tabular}

a. For further information see www2.warwick.ac.uk/fac/med/research/csri/ethnicityhealth/aspects_diversity/models/. 
called 'ad hoc liaison'; questions and answers are short. When English and Spanish are the language pair, the simple question 'What is your date of birth?' becomes ‘¿Cuál es su fecha de nacimiento?' In more extended utterances, such as history-taking, the usual technique is called 'consecutive with note-taking'. Here, Speaker A says several sentences at a time; the interpreter takes aide-memoire notes and interprets at the end of that time. Speaker B replies by the same method. The golden rule for speakers is to finish the thought before pausing for interpretation. This is a familiar system for ITALS users but has the disadvantage of decoupling the meanings of the words from the information sent by tone of voice, posture, gesture and facial expression.

The non-verbal elements are available to the doctor significantly sooner than the meaning of the words. The meanings of non-verbal signals are not always obvious and may be culture-bound. Where this decoupling might cause a significant misunderstanding or loss of information, the interpreter should intervene appropriately to clarify or explain. For instance, nodding the head means different things in different cultures: in many cultures nodding means 'yes', in some cultures an up-down jerk of the chin is an interrogative, and in other cultures it means 'no'; the interpreter might point this out, doing so in both languages, so that nobody feels excluded. ${ }^{8}$

A technique known as 'whispered simultaneous interpreting' saves time and makes comprehension easier because the meaning of the words can be understood almost at the same time as the non-verbal signals. In this technique, Speaker A speaks at a normal pace, with occasional brief catch-up pauses, while the interpreter listens, switches the language and speaks - all at the same time. Little empirical research exists into how the interpreter manages this constant flow of information, ${ }^{9-11}$ but it does not take long for a clinician or end-user to learn their part in it, which is mostly a question of timing the pauses.

Elderkin-Thompson and colleagues ${ }^{12}$ quote Hornberger et al: 'When used by medically trained experts, simultaneous interpreting produces fewer errors and greater satisfaction among both physicians and nonEnglish-speaking patients' (p. 1355).

Some patients cannot accept whispering or note-taking, which leaves the ad hoc liaison technique. Ad hoc liaison is harder work for all parties because the speaker delivers one small chunk of sentence at a time. The chunks are often so small that the overall meaning of a sentence or an idea is difficult to reassemble in the target language without constant correction, as described above.

When patients refuse the services of an ITALS worker, as a result of lack of trust, it may be due to not having experienced the work of a professional translator before. ${ }^{13}$ If the interpreter is part of the local speech community, the patient may not grasp the idea of the interpreter's professional commitment to confidentiality and may not trust them with secrets.

\section{Looking to the future}

Greenhalgh and colleagues $^{14}$ point out that failed communicative action is often caused by institutional and state influence: '. . . system imperatives deriving from economy and state can so circumscribe behaviours in medical settings as to render communicative action all but impossible'. ${ }^{5}$ Government policy on interpreting is indeterminate and, although implying a wish for high standards, does not provide a system of quality assurance, and so supply is effectively left to the market.

A recent decision by the British Ministry of Justice to sign a framework agreement with a large commercial agency, making it the sole employer of court and many police interpreters, while also acting as the language and skills assessor and regulator, restores the situation that existed 30 years ago. Unlike Sweden (see www. regeringen.se/sb/d/3288/a/19564), the UK has never had a coherent policy on standards of interpreting in healthcare or any other part of the public sector. This is driving qualified and experienced legal interpreters out of the profession. ${ }^{15}$ Clear government policy on training for interpreters across the public sector is necessary at the national level. It is not enough to leave it to the market. If markets are left to themselves, people commissioning an external service will go for the cheapest option. Qualified interpreters who have outgoings such as insurance and subscriptions cannot compete on price with those who do not. No pay differential is made by the agencies that employ them. Other professions within the multidisciplinary teams at work in healthcare have nationally set training curricula and standards, but locally delivered training and interpreters' education and training should be coordinated in the same way.

A collaborative effort between medical professional bodies and relevant linguists' professional associations to address these challenges would drive up and sustain high standards. For example, the Institute of Translation and Interpreting (www.iti.org.uk) and the Chartered Institute of Linguists (www.iol.org.uk) have national and international recognition and long expertise in the field; the latter has just celebrated its centenary. Mutually developed working practices and joint training would foster the mutual understanding and respect needed for the full integration of interpreters in multidisciplinary teams. Joint representations to government would be more powerful than just the voice of interpreters.

\section{About the authors}

Jan Cambridge, professional interpreter and interpreter trainer; Fellow of the Chartered Institute of Linguistics and the Institute of Translation \& Interpreting; and registered public service interpreter. Swaran P. Singh, Head of the Division of Mental Health and Wellbeing, Warwick Medical School; Honorary Consultant Psychiatrist, Birmingham and Solihull Mental Health Foundation Trust; and Professor of Social and Community Psychiatry. Mark Johnson, Professor of Diversity in Health and Care, De Montfort University, Leicester, and Director of the Centre for Evidence in Ethnicity Health and Diversity, Mary Seacole Research Centre; and Specialist Advisor on Equalities to the National Institute for Health and Clinical Excellence.

\section{References}

1 McGurk H, McDonald J. Hearing lips and seeing voices. Nature 1976; 264: $746-8$

2 Woodhouse L, Hickson L, Dodd B. Review of visual speech perception by hearing and hearing-impaired people: clinical implications. Int J Language Commun Disord 2009; 44: 253-70. 
3 Cambridge J. Information loss in bilingual medical interviews through an untrained interpreter. Translator 1999; 5: 202-19.

4 Divi C, Koss RG, Schmaltz SP, Loeb JM. Language proficiency and adverse events in US hospitals: a pilot study. Int J Qual Health Care 2007; 19: 60-7.

5 Flores G. The impact of medical interpreter services on the quality of health care: a systematic review. Med Care Res Rev 2005; 62: 255-99.

6 National Centre for Languages (CiLT). Standards, Qualifications and Frameworks. CiLT, 2005 (http://www.cilt.org.uk/home/standards_ and_qualifications.aspx).

7 Aspinall PJ. Language ability: a neglected dimension in the profiling of populations and health service users. Health Educ J 2007; 66: 17.

8 Archer D. Unspoken diversity: cultural differences in gestures. Qual Sociol 1997; 20: 79-105.

9 Gile D. Conference interpreting as a cognitive management problem. In The Interpreting Studies Reader (eds F Pöchhacker, M Shlesinger): 16276. Routledge, 1997.

10 Collados Aís A. Quality assessment in simultaneous interpreting: the importance of non-verbal communication. In The Interpreting Studies Reader (eds F Pöchhacker, M Shlesinger): 326-36. Routledge, 1997.
11 Moser-Mercer B. Process models in simultaneous interpretation. In The Interpreting Studies Reader (eds F Pöchhacker, M Shlesinger): 148-61. Routledge, 1997.

12 Elderkin-Thompson $\mathrm{V}$, Cohen Silver $\mathrm{R}$, Waitzkin $\mathrm{H}$. When nurses double as interpreters: a study of Spanish-speaking patients in a US primary care setting. Soc Sci Med 2001; 52: 1343-58.

13 Khoei EM, Richters J. Concepts of sexuality and health among Iranian women in Australia. Aust Fam Physician 2008; 37: 190-2.

14 Greenhalgh T, Robb N, Scambler G. Communicative and strategic action in interpreted consultations in primary health care: a Habermasian perspective. Soc Sci Med 2006; 63: 1170-87.

15 Anon. The 1986 Administrative Procedure Act (including subsequent amendments). Cited in Swedish Country report to EU Fundamental Rights Agency 1986. Available at http://www.sweden.gov.se/sb/d/574/a/ 64892.

16 Mikkelson $\mathrm{H}$. The professionalization of community interpreting. In Global Vision: Proceedings of the 37th Annual Conference of the American Translators Association (ed. MM Jérôme-O'Keefe): 77-89. American Translators Association, 1996.

\title{
Interpreting in psychiatry: a clinician's perspective Commentary on ... The need for measurable standards in mental health interpreting ${ }^{\dagger}$
}

\author{
Seamus MacSuibhne ${ }^{1}$
}

The Psychiatrist (2012), 36, 124-125, doi: 10.1192/pb.bp.111.038117

${ }^{1}$ St Luke's Hospital, Kilkenny, Ireland Correspondence to Seamus MacSuibhne (seamus.macsuibhne@ucd.ie)

First received 1 Dec 2011, accepted 17 Jan 2012

\begin{abstract}
Summary Cambridge et al describe the neglect into which consideration of the role of the interpreter in the encounter between patient and mental health professional has fallen. Much of what little literature exists on the topic is concerned with adverse events related to interpreting, rather than the interpreter's role per se. Cambridge et al are to be commended for a paper which may help bridge the gap between theory and practice of interpretation on the one side and psychiatry on the other.
\end{abstract}

Declaration of interest None.
Understanding what is being said in the interaction between doctor and patient is crucial for both parties. This is particularly so in psychiatry, where both the form and content of what is being said by both patient and doctor often relates to the most personal and private matters. The power of psychiatrists to, in certain circumstances, deprive a person of their liberty (a decision in which what the person says and how they say it plays a key role) gives a particular urgency to this need for mutual comprehension. All the terminology of which psychiatric assessments are constructed - 'suicidality', 'capacity', 'ruminations', 'preoccupations', 'delusions', 'overvalued ideas' and so on depend on language for their assessment and articulation.

"See editorial, pp. 121-124, this issue.
And they depend on a confidence in the ability of the psychiatrist to understand what the person is saying.

When an interpreter is required, there is a further aspect to the interaction; the presence of an 'other' who mediates between the patient and the interviewer. A systematic review of the use of interpreters in medical practice overall found positive benefits of professional interpreters on communication (reducing errors and improving comprehension), healthcare utilisation, clinical outcomes and satisfaction with care. ${ }^{1}$ Given this, and also the sociological interest in power disparities between doctor and patient in mental health, it is something of a surprise that the literature on interpreting in this context is so scanty.

Drennan \& Swartz ${ }^{2}$ provide, in a South African context, an ethnological account of the institutional management of 